\title{
К 20-летию ВТО:
}

\section{критический взгляд на практику Органа по разрешению споров}

Рассмотрена деятельность Органа по разрешению споров ВТО с критической точки зрения, представляющего собой, по мнению автора, своеобразный институт, сочетающий дипломатические и судебные компоненты. Именно с этих позиций проанализированы такие ее особенности, как специфический характер выносимых решений, основанный на ответных мерах механизм выполнения решений, эволюция роли и видов мировых соглашений, заключаемых в рамках ВТО.

Ключевые слова: Орган по разрешению споров ВТО, обязательность решений, санкиии, мировые соглашения.

\section{Введение}

В 2015 г. будет отмечаться 20-летие создания как собственно ВТО, так и созданного в ее рамках Органа по разрешению споров (ОРС). Такая круглая дата - сама по себе уже хороший повод попытаться объективно оценить успехи и недостатки ОРС и даже предложить новый взгляд на ОРС, который сможет внести свой вклад в выработку прагматичного подхода России к участию в спорах в рамках ВТО.

Бесспорно, что ОРС является своего рода жемчужиной в короне ВТО [1]. Согласно доминирующим оценкам отечественных исследователей при описании ОРС система рассмотрения споров в ВТО на сегодня является наиболее совершенной структурой по разрешению международных споров, выступая де-факто международным торговым судом универсального характера [2, с. 158]. Можно также привести мнение А.С. Смбатян, которая пишет, что разрешение споров в ОРС - один из самых эффективных из когда-либо существовавших механизмов урегулирования межгосударственных споров, сопоставимых разве что с Европейским судом по правам человека (ЕСПЧ) $[3$, c. 7].

1 Исполинов Алексей Станиславович - заведующий Кафедрой международного права Юридического факультета МГУ им. М.В. Ломоносова, кандидат юридических наук, доцент. 
Однако такой подход является недостаточно эффективным для выявления и оценки существующих очевидных проблем в функционировании ОРС. Этот подход также мало что дает как для объяснения, чем вызваны те или иные предложения по реформированию ОРС, которые активно обсуждаются в ходе Дохийского раунда, так и для понимания того, зачем вообще нужно реформировать ОРС. Автор полагает, что отправной точкой при анализе ОРС должен стать тезис о том, что ОРС по-прежнему остается крайне своеобразным гибридным образованием, сочетающим дипломатические и судебные компоненты [4, с. 69]. К дипломатическим элементам можно отнести обязательность проведения консультаций, требование к третейским группам всячески содействовать поиску компромисса между спорящими сторонами, конфиденциальность слушаний, специфику санкций в ВТО. При этом баланс между судебным и дипломатическим компонентами не есть статическая величина, он меняется с течением времени в зависимости от обстоятельств, что придает системе столь необходимые гибкость и устойчивость. И если в первые годы существования ОРС баланс был сдвинут в пользу судебного компонента, то за последние годы маятник качнулся в другую сторону. Именно этим объясняется как общее снижение количества споров, передаваемых для разрешения в ОРС, так и значительное удлинение сроков их рассмотрения, далеко выходящее за пределы, установленные при создании ОРС. Понимание ОРС как гибридной системы объясняет и такие ее особенности, как:

- специфический характер выносимых решений;

- весьма своеобразный санкционный режим;

- эволюция роли и видов мировых соглашений, заключаемых в рамках ВТО.

Об этих специфических чертах названной гибридной системы и пойдет речь далее.

\section{1. Общая статистика}

С момента создания ВТО в 1995 г. и по 1 августа 2014 г. государства подали в ОРС 482 жалобы [5]. При этом статистика показывает, что с начала 2000-х годов среднее количество поданных за год жалоб постепенно снижается. Пик был достигнут в первые годы деятельности ОРС (1995-1999), когда в среднем подавалось по 37 жалоб в год. В 2010-2012 гг. ОРС ежегодно получал уже в среднем по 17 жалоб [6, с. 1-11]. Наиболее активно используют возможности ОРС США и ЕС, совместная доля которых среди общего числа поданных жалоб превышает 40\%. Они же являются ответчиками более чем в 40\% споров [там же]. При этом исследователи единодушно отмечают, что за последние годы споры стали гораздо более сложными по новизне толкуемых положений и фактам, лежащим в основе споров, количеству требований, задействованных в споре соглашений и вовлеченных в спор сторон [7]. Отсюда и значительное увеличение сроков рассмотрения споров при общем снижении их количества. Предельные сроки рассмотрения дел в ОРС, 
которые были установлены в Договоренности о правилах и процедурах, регулирующих разрешение споров (далее - Договоренность), и которые до сих пор приводятся как одно из достоинств нынешней системы рассмотрения споров в ВТО, давно не соблюдаются ни третейскими группами, ни Апелляционным органом. Уже сейчас средний срок рассмотрения дела (включая вопросы об исполнении решения ОРС и эквивалентности санкций) составляет три-четыре года. Своего рода рекорд был установлен при рассмотрении дела US - Cotton, где с момента образования третейской группы и до разрешения Бразилии применить санкции прошло 6,5 лет. Однако и он будет перекрыт идущими до сих пор разбирательствами между ЕС и США в отношении субсидий компаниям Boeing (начато в 2005 г., доклад об исполнении решения ОРС ВТО (Compliance proceedings) ожидается к середине 2015 г.) [8] и Airbus (начато в октябре 2004 г., доклад об исполнении решения ОРС предполагается к концу 2014 г.) [9].

\section{2. Формирование третейских групп}

Пожалуй, самой большой организационной проблемой ОРС остается порядок формирования третейских групп, выступающих первой инстанцией при разрешении споров в ВТО. Договоренность предусматривает, что третейские группы формируются из высококвалифицированных специалистов, предлагаемых Секретариатом, который ведет индикативный (необязательный) список кандидатов, предлагаемых государствами. Очень важную роль играет требование о том, что в состав третейской группы не могут входить граждане тех государств, которые являются либо участниками рассматриваемого группой спора, либо выступают в этом споре третьими сторонами. Если согласия сторон спора в отношении состава третейской группы не достигается в течение 20 дней, любая сторона может просить Генерального директора ВТО сформировать новую группу.

Реализация этих положений на практике привела к крайне противоречивым результатам. Уже с 1997 г. Генеральный директор ВТО формировал каждую вторую группу, а с 2002 г. таким способом создавалось более 2/3 групп. На практике процедура формирования третейской группы все чаще оказывается трудоемким и длительным процессом, хотя Договоренность предусматривает, что стороны спора не могут возражать против конкретных кандидатур только в силу веских причин. Тем не менее спорящие стороны обычно трактуют данное положение максимально широко, зачастую под различными предлогами блокируя предлагаемые кандидатуры. Например, известны случаи, когда в спорах с участием ЕC предложенная кандидатура панелиста блокировалась другой стороной спора лишь по причине того, что его страна уже подала заявку на вступление в ЕС. Наиболее часто встречающимся основанием для отказа является участие панелистов в раз-

решении других споров в ВТО, особенно если выносимые ими решения были не в пользу государства, решившего заблокировать их кандидатуры. 
Несмотря на то, что в соответствии с Договоренностью Генеральный директор ВТО формирует группу в течение 30 дней, на практике этот срок уже давно превышает 70-80 дней, а в одном случае он составил рекордные 274 (!) дня [10]. Такое удлинение сроков вызвано тем, что все более проблематично найти квалифицированных панелистов, которые не были бы гражданами ни спорящих стран, ни стран, выступающих в споре третьими сторонами. Кстати, именно этим объясняется то, что группы всегда формировались из трех человек, хотя Договоренность в принципе разрешает и группу из пяти панелистов.

За 1995-2012 гг. членами третейских групп стали 516 человек, при этом 221 были из семи стран (Новая Зеландия, Швейцария, Канада, Бразилия, Чили и ЮАР) [6, с. 11]. Так как наиболее активно в ОРС ВТО выступают США и ЕС, то вполне объяснимо, что граждане США становились членами третейской группы только 12 раз. В середине 2000-х годов портрет среднестатистического члена третейской группы выглядел так: действующий или бывший правительственный чиновник из небольшого развитого государства $[11$, с. 431]. В последние годы география членов третейских групп несколько расширилась за счет представителей развивающихся стран, среди них стали чаще встречаться научные работники и практикующие юристы. В среднем один и тот же член третейской группы назначался в 2,2 группы, при этом в 55\% сформированных групп оказывается два панелиста или больше, для которых это вообще первое назначение в ОРС ВТО [12, с. 582].

Еще 10 лет назад исследователи отмечали, что в результате использования такого подхода к формированию третейских групп и возрастающей доктринальной сложности споров в ВТО члены третейских групп все меньше и меньше ориентируются во всех деталях практики споров в ГАТТ-ВТО, насчитывающей сейчас сотни решений [13, с. 105]. Кроме того, распространенная практика создания третейских групп из действующих правительственных чиновников привела к тому, что они не располагают ни временем, ни желанием глубоко исследовать и анализировать все обстоятельства дела, а также предшествующую практику. Немаловажным обстоятельством, как минимум, не повышающим интерес панелистов к своим обязанностям, является скромная (по сравнению с коммерческими или инвестиционными арбитражами) оплата их труда. Она уже длительное время остается на уровне 600 швейцарских франков за день их работы в этом качестве [13, c. 146]. При этом в случае назначения в состав третейских групп государственные служащие лишены и этого вознаграждения (им компенсируются только затраты на проезд и проживание).

Bсе перечисленное в значительной степени способствует появлению серьезных ошибок третейских групп при правовой оценке обстоятельств дела. Иногда это - ошибки в элементарных вопросах, предопределяющих выводы группы. Например, в своем решении по делу Australia-salmon третейская группа сосредоточилась лишь на анализе импорта лосося горячего копчения, 
хотя в жалобе речь шла об импорте свежего, замороженного и охлажденного лосося [14]. Многие специалисты отмечают, что частота и масштаб ошибок третейских групп вызывают серьезное беспокойство, а качество выносимых ими решений нуждается в существенном улучшении [15, с. 145].

ОРС ВТО старается решить эту проблему несколькими путями, которые, в свою очередь, могут дать побочные эффекты. Во-первых, своеобразным голкипером на пути ошибок третейских групп старается выступать Апелляционный орган. К сожалению, выбираемые им иной раз тон и характер комментариев в отношении выводов третейских групп мало способствуют появлению эффективного диалога между первой и второй инстанциями ОРС. Так, в одном своем широко известном решении Апелляционный орган назвал выводы группы «абсурдом» [16]. В другом решении Апелляционный орган не без сарказма отметил, что «группа в этом деле создала своей собственный принцип толкования, не соответствующий ни общепринятым правилам толкования норм международного права, ни практике ГАТТBTO» [17]. Подобная практика приводит к тому, что третейские группы иногда попросту уклоняются от глубокого анализа обстоятельств рассматриваемого спора, фактически перекладывая ответственность на Апелляционный орган. Последующий же все чаще сам исследует факты и доказательства, тратя на это дополнительное время. Исследователи говорят о том, что Апелляционный орган рискует постепенно превратиться в суд первой и последней инстанции в ВТО [7, с. 4].

Во-вторых, Секретариат ВТО старается помочь третейским группам за счет массированной юридической поддержки, фактически готовя им аргументацию и проект решения, чем освобождает членов групп от необходимости внимательно изучать всю накопившуюся практику разрешения споров в ГАТТ-ВТО. С одной стороны, такая помощь приветствуется членами третейских групп, многие из которых в силу своей занятости могут участвовать в заседаниях лишь в режиме телеконференции. С другой стороны, такой подход приводит к тому, что члены третейских групп зачастую оказываются фактически в зависимости от сотрудников Секретариата. В результате увеличивается риск того, что решение группы будет выражать не столько мнение ее членов, сколько представления сотрудников Секретариата о том, как этот спор должен быть разрешен.

Bсе это дает серьезные основания поставить под сомнение эффективность работы третейских групп, объективность и беспристрастность их решений и даже их легитимность. Отсюда и предложения о создании постоянно действующей третейской группы [18, с. 187-202; 19, с. 211-214, 20, с. 203-209] или введение ограниченного (25-30 человек) и стабильного (на 6-8 лет) списка панелистов, из которого и будут формироваться третейские группы. В этом случае требования к их квалификации, а также условия и порядок их оплаты должны быть такими же, как в случае с членами Апелляционного органа. Это позволит не только повысить качество выносимых группами решений, 
но и реализовать одно из предложений о реформе ОРС ВТО: дать Апелляционному органу право возвращать дело обратно на первую инстанцию. Кроме того, все громче раздаются голоса о пересмотре правила о неучастии в рассмотрении спора граждан спорящих государств, так как это исключает во многих случаях привлечение в качестве членов третейских групп наиболее известных и авторитетных специалистов по праву ВТО из ЕС и США [21].

\section{3. Вопрос о правовых последствиях решений ОРС}

В ст. 19.1 Договоренности говорится, что третейская группа, а вслед за ней и Апелляционный орган лишь устанавливают факт несоответствия оспоренной внутренней меры праву ВТО и рекомендуют государству устранить нарушения в течение разумного периода (но при этом не обязывают и не требуют сделать это). Если оспоренную внутреннюю меру невозможно отменить или изменить незамедлительно, проигравшая сторона выплачивает компенсацию, которая должна рассматриваться как временная мера до полного устранения выявленного нарушения. В исключительных случаях, когда решение ОРС не исполняется, выигравшее спор государство может запросить у ОРС разрешение на применение санкций.

Однако мнения исследователей в отношении трактовки этих положений Договоренности разделились. Широкую известность получила дискуссия о существовании выбора у государств после решения ОРС и правомерности подобного выбора. Так, по мнению Дж. Белло, у государства, чьи меры признаны не соответствующими праву ВТО, в этом случае есть целый набор опций для дальнейших действий [22, с. 417] (или «меню для выбора», как остроумно заметил поддержавший ее С. Чарновиц [23, с. 56]). Конечно, среди этих опций наиболее предпочтительным является исполнение решения ОРС. Но при этом государство может попытаться сохранить оспоренную меру, обсудив с выигравшим государством вопрос о компенсации (т.е. фактически откупиться), либо вообще отказаться что-то менять. Тогда такое государство должно быть готовым к тому, что против него будут применены санкции. Сторонники данного подхода выступают за то, чтобы толковать соответствующие положения Договоренности именно как разрешающие государствам сделать такой выбор, если внутренняя политика или изменившиеся экономические обстоятельства вынуждают сделать это. В таком случае государства-члены ВТО вправе реализовать свои суверенные права и принять меры, идущие вразрез с соглашением ВТО, при условии, что это государство как-то компенсирует ущерб своих торговых партнеров или подвергнется встречным санкциям.

Несмотря на то, что подобная точка зрения была подвергнута резкой критике [24], автор данной статьи все же полагает, что дальнейшая практика государств в отношении исполнения решений ОРС все больше и больше доказывает правоту Дж. Белло и ее сторонников. 
Из всех вынесенных ОРС решений, признававших факт нарушения государствами своих обязательств в рамках ВТО, только в семи случаях проводились специальные дополнительные процедуры по проверке исполнения принятых решений и лишь в пяти - были установлены факты неисполнения. Разрешение на применение санкций выдавалось всего в пяти делах [25]. Из приведенных данных видно, что в подавляющем большинстве случаев государства все же по разным причинам заинтересованы в исполнении принятого ОРС решения.

В Договоренности говорится, что к компенсации стороны прибегают лишь тогда, когда оспоренную внутреннюю меру невозможно отменить или изменить незамедлительно, и компенсация должна рассматриваться как временная мера до полного исполнения решения ОРС. Причем предполагалось, что подобная компенсация должна быть в форме тарифных или иных уступок государству-заявителю. Однако в реальности практика (правда, пока крайне немногочисленная) пошла по пути финансовой компенсации. Наиболее известным примером остается единовременная выплата 3,3 млн долл. США, произведенная в 2003 г. после проигранного ими спора с ЕС в отношении ст. 105(5) Закона США об авторских правах [26] ${ }^{1}$. Другим примером является компенсация в виде ежегодной выплаты 147,3 млн долл., уплаченная в рамках соглашения между США и Бразилией после проигранного американцами спора по делу United States - Subsidies on Upland Cotton [27]. Следует отметить, что в обоих случаях выплата компенсации не сопровождалась отменой оспоренной меры. Данное обстоятельство также позволяет утверждать, что проигравшее государство таким образом заплатило своего рода отступные. Вместе с тем практика последних лет говорит о том, что государства все же идут на предоставление определенных тарифных и нетарифных уступок выигравшему государству. В этом случае подобные уступки делаются в рамках общего пакета по урегулированию спора и сохранению оспоренной меры. Так, в рамках того же соглашения между Бразилией и США по урегулированию спора по делу United States - Subsidies on Upland Cotton американская сторона согласилась пересмотреть свои санитарные меры, отграничивающие импорт мяса из некоторых штатов Бразилии [28]. Многолетний спор в отношении запрета ЕС на импорт говядины, выращенной с использованием гормонов роста, был закончен подписанием специального соглашения в 2013 г., в рамках которого ЕС сохранял свой запрет, а принятые против ЕС санкции постепенно отменялись в обмен на повышение для США и Канады квоты на ввоз в ЕС высококачественной говядины [29].

1 Эта выплата покрывала период до 31 декабря 2004 г., после истечения которого стороны до сих пор продолжают консультации по поводу исполнения решения. 
Наконец, исследователи отмечают растущее число случаев открытого игнорирования решений ОРС либо их длительного неисполнения. Такой выбор был сделан ЕС, когда введенный им запрет на импорт говядины, выращенной с использованием гормонов, был успешно обжалован США и Канадой в ОРС. ЕС так и не пошел на отмену веденного им запрета, будучи уверенным в своей правоте, несмотря на введенные против него санкции, и в итоге выстоял в этом почти 15-летнем торговом конфликте. Длившаяся около 20 лет «банановая война» по поводу упорного нежелания ЕС отказаться от торговых преференций в отношении импорта бананов, предоставленных бывшим европейским колониям, также в итоге завершилась подписанием мирового соглашения. И это несмотря на 12 (!) последовательных решений, вынесенных начиная с 1993 г. в рамках ГАТТ, а затем ВТО третейскими группами, Апелляционным органом и арбитражами, признававшими режим импорта бананов в ЕС не соответствующим нормам ГАТТ-ВТО.

Очевидно, что также не будет исполнено решение ОРС, принятое по жалобе Антигуа, крошечного государства Карибского бассейна, которое успешно оспорило в ВТО меры, предпринятые США в отношении трансграничного оказания услуг в сфере игорного бизнеса. Несмотря на то, что решение было принято еще в 2005 г., нет никаких признаков того, что США хоть как-то стремились его исполнить, даже после того, как Антигуа запросило в ВТО и получило в январе 2013 г. право на введение ответных санкций в отношении США. Речь идет о том, что Антигуа, судя про всему, переоценило возможности своего легалистского подхода и не учло, что для США риски потери лица от исполнения решения, вынесенного в пользу крошечного государства (причем исполнения под угрозой санкций со стороны этого государства!), в данном случае сто́ят гораздо выше, чем имиджевые и экономические потери от полного игнорирования этого решения. Можно предположить, что правительство Антигуа упустило подходящий момент, когда вопрос еще можно было решить путем переговоров. Если же говорить о практике США в целом, то на начало 2012 г. было 14 решений ОРС, еще ими не исполненных или ненадлежаще исполненных ${ }^{1}$ [30].

\section{4. Специфика механизма санкций в ВТО}

К весьма примечательным особенностям системы рассмотрения споров в ВТО, также вызывающим горячие дискуссии, нужно отнести и те ответные меры, которые разрешается использовать, если государство уклоняется от исполнения решения ОРС. Как довольно красочно пишет Дж. Белло,

1 Применительно к этим решениям уже истекал тибо истек срок, отведенный США для приведения своего законодательства в соответствие с решением ОРС ВТО, или США изменили свое законодательство, но это не удовлетворило государство-заявителя жалобь. 
вынесение третейской группой решения против государства совершенно не означает «перспективу лишения свободы, введения обеспечительных мер, необходимости возместить ущерб или принудительного исполнения решения судебными приставами. В рамках ВТО отсутствуют тюремные камеры, освобождение под залог, голубые каски, а также полицейские дубинки или слезоточивый газ» [22, с. 417].

В Договоренности говорится о применении ответных мер в отношении государства-нарушителя как о крайней мере, к которой можно прибегать только государству-заявителю и только с разрешения ОРС. Относительно того, что именно нужно понимать под ответными мерами, в Договоренности содержится весьма тяжеловесная фраза об одностороннем приостановлении или аннулировании государством-заявителем уступок, сделанных в рамках соглашений ВТО. Однако в литературе и практике уже устоялся и активно применяется термин «санкции», который как нельзя лучше характеризует суть режима санкций ВТО. История применения таких мер в рамках организация показывает, что в подавляющем большинстве случаев речь идет о применении государством-заявителем повышенных (до 100\%) пошлин на товары, импортируемые из страны-нарушителя. Так, после отказа ЕС отменить свой запрет на импорт мяса, выращенного с использованием гормонов роста, США и Канада ввели повышенные пошлины на различные товары из ЕС, включая сырой трюфель, сыр Рокфор, шоколад, соки, джемы. Еще более обширный список товаров был использован США в деле о бананах, включавший банные принадлежности, бумажники и ручные сумки, картон и изделия из него, постельное белье, аккумуляторные батареи и машины для приготовления кофе.

Однако самой главной спецификой механизма санкций в ВТО является то, что он в принципе не предусматривает какое-либо возмещение ущерба, вызванного применением государством-нарушителем оспоренной меры. Таким образом, санкции по определению не могут носить ретроспективный характер.

Критикуя существующую систему санкций в ВТО, многие исследователи говорят о ее врожденной несправедливости, проявляющейся в том, что, приватизируя санкции и тем самым передавая возмездие в руки выигравшей стороны, ВТО лишает себя верховенства права и вместо этого вводит правило джунглей в международную политику. Среди конкретных недостатков обычно указываются следующие.

Во-первых, санкции не всегда приводят к достижению желаемого результата. Как уже отмечалось, ЕС так и не пошел на отмену своего запрета на импорт говядины, выращенной с использованием гормонов роста, даже после того, как США и Канада (страны, обратившиеся с жалобой в ВТО) получили разрешение применить повышенные пошлины на товары, происходящие из стран-членов ЕС. Антигуа так и не решилась вводить санкции 
против США, на которые уже было получено разрешение ОРС. Во многом это было связано с тем, что в стране с населением в 90 тыс. человек ввод санкций в виде снятия внутренней защиты на объекты интеллектуальной собственности, принадлежащие американским компаниям, выглядел бы несколько комично. Введение санкций лишь усилило бы мнение о том, что конечной целью для Антигуа в этом деле было получение солидных отступных от США. Кроме того, исследователи отмечают растущее число случаев, когда государства выбирают открытое неисполнение решений ОРС даже под угрозой применения санкций [31, с. 142].

Во-вторых, государства научились использовать особенности процедуры рассмотрения споров в ВТО для того, чтобы максимально оттянуть момент введения санкций, и только после этого идут на отмену предпринятой ими меры. Ранее уже говорилось о значительном превышении сроков рассмотрения всех споров в ОРС ВТО. В такой ситуации государства зачастую оказываются перед большим искушением использовать указанные недостатки системы санкций в собственных целях. С учетом значительных сроков рассмотрения споров в ОРС и отсутствия ретроспективных санкций государствам уже нет необходимости прибегать к специальным защитным мерам, порядок применения которых достаточно сложен и регулируется соответствующим соглашением. Достаточно лишь запастись некоторой долей цинизма и принять любую необходимую меру, прекрасно понимая при этом, что данная мера идет вразрез с предписаниями ВТО. Затем же, после длительного рассмотрения спора в ОРС, эту меру можно спокойно отменить, не дожидаясь применения санкций и не неся никакой ответственности за ее многолетнее применение. Как отметил в свое время президент США Дж. Буш-младший, отменяя оспоренную в ОРС специальную защитную меру по поддержке сталелитейной отрасли, «сталелитейная промышленность самым разумным способом использовала 21 месяц передышки (срок, в течение которого рассматривался спор в отношении этой меры в третейской группе, а затем в Апелляционном органе). Эти меры уже достигли своих целей, самое время их отменить» [32]. В данной ситуации вполне можно предположить, что приведенные в начале статьи цифры, свидетельствующие о популярности обращений в ОРС и об исполнении принятых ОРС решений, говорят не столько об эффектности системы рассмотрения споров, сколько о том, что государства научились использовать специфику системы санкций в ВТО в своих целях. Поэтому далеко не случайным кажется тот факт, что на практике еще ни разу не был задействован механизм рассмотрения торговых споров по существу в специально создаваемом по согласию спорящих сторон арбитраже (ст. 25 Договоренности предусматривает создание такого арбитража «для ускоренного рассмотрения спора», при этом его решения должны быть окончательными).

В то же время многие исследователи позитивно оценивают существующий режим санкций в ВТО, отмечая, что отсутствие обязанности возмещать ущерб и упущенную выгоду является весьма серьезным стимулом для 
государств передавать свои споры в ОРС для уточнения каких-либо положений соглашений ВТО [33]. Автор склонен присоединиться к парадоксальному мнению Дж. Транчмана, указывающего на то, что государства, вводя именно такую систему санкций, вполне осознанно решили оставить себе пространство для маневра при исполнении решений ОРС: «это (система санкций в ВТО. - Прим. А.И.) не является апологией плохой проработанности, непоследовательности или других проблем Договоренности. Это реалистическое признание того, что право и политика должны мирно сосуществовать и что нирвана абсолютной исполнимости (решений ОРС. - Прим А.И.) является химерой» $[34$, c. 678]. По мнению автора, это лишний раз подтверждает гибридный характер ОРС ВТО, о котором уже говорилось выше.

\section{5. Практика заключения мировых соглашений (решений, принятых по взаимному согласию)}

Уместно будет напомнить о том, что в ст. 3.7 Договоренности установлена некая иерархия путей устранения нарушений норм ВТО, в которой именно компромиссное решение спора, безусловно, является наиболее предпочтительным. Анализ положений Договоренности показывает, что стороны спора вправе прийти к компромиссу не только в любой момент рассмотрения спора в третейской группе, но и на стадии исполнения решения ОРС. На сегодня примерно 20\% споров, переданных государствами для разрешения в ОРС, закончилось принятием сторонами решений, принятых по взаимному согласию (mutually agreed solutions). Эти решения весьма напоминают мировые соглашения, заключаемые в национальных судах, поэтому у автора есть все основания использовать в дальнейшем именно этот термин [4, c. 70]. Из примерно 80 мировых соглашений, официально представленных в ОРС, половина была заключена на стадии консультаций, остальные примерно в равной пропорции на стадии третейской группы или уже на этапе исполнения решения ОРС. Обычно в этих соглашениях стороны договариваются о различных процедурах и сроках приведения оспариваемой меры в соответствие с правилами ВТО. Однако помимо этого мировые соглашения могут содержать положения, накладывающие на стороны дополнительные обязательства сверх тех, что предусмотрены соглашениями ВТО. Используя терминологию из документов о присоединении новых стран к организации, такие положения получили название «ВТО минус мировое соглашение». Например, в мировом соглашении между Канадой и США по делу Softwood Lumber [35] стороны согласились отказаться от своего права на дальнейшее обращение в ОРС по данному спору. Аналогичный же запрет на использование ОРС для оценки исполнения сторонами своих обязанностей предусматривает и уже упомянутое выше мировое соглашение по спору о запрете ЕС на импорт говядины.

Мировое соглашение может также предусматривать дополнительные средства и механизмы контроля по сравнению с тем, что предусмотрено согла- 
шениями ВТО («ВТО плюс мировое соглашение»). Кроме того, в мировых соглашениях стороны могут предусматривать прекращение споров не только в ВТО, но и в других судах. Например, все в том же деле Softwood Lumber стороны договорились прекратить 20 судебных процессов, идущих в национальных судах, а также в ВТО и НАФТА.

Договоренность требует, чтобы такие соглашения были совместимы с соглашениями ВТО и не аннулировали или не сокращали бы выгоды третьих государств, вытекающие из данных соглашений. Для этого вводится обязанность извещать Секретариат ВТО о достижении таких соглашений.

Здесь нужно отметить два нюанса. Во-первых, если говорить о совместимости мировых соглашений с соглашениями ВТО, то практика ОРС показывает, что совместимыми будут считаться такие соглашения, которые либо не противоречат праву ВТО (WTO-consistent), либо являются разрешенными отступлениями (изъятиями) из соглашений ВТО. Во-вторых, из практики последних лет следует, что в силу целого ряда причин такие требования к мировым соглашениям не устраивают государства. Это повлекло появление новых, не предусмотренных Договоренностью мировых соглашений или мировых соглашений, не отвечающих в значительной своей части упомянутым выше требованиям. К ним можно отнести промежуточные соглашения, предусматривающие целый ряд шагов, которые стороны намерены предпринять, и только по мере их выполнения будет достигнуто финальное мировое соглашение, о котором и будет уведомлен Секретариат ВТО. К таким промежуточным соглашениям можно отнести Рамочное соглашение между Бразилией и США по уже упоминавшемуся спору US-Uppland Cotton [36]. Это соглашение было достигнуто после того, как Бразилия успешно оспорила программу субсидирования производителей хлопка и даже получила разрешение ОРС на применение санкций. В обмен на фактический отказ от применения санкций США приняли на себя обязательство выплачивать Бразилии 147 млн долл. ежегодно и информировать о шагах по сворачиванию оспоренной программы. К новому типу мировых соглашений можно отнести и джентельменское соглашение между Бразилией и Канадой в отношении взаимных обвинений по поводу программ субсидирования самолетов. Бразилия успешно оспорила в ВТО канадскую программу субсидирования экспорта самолетов Bombardier. В свою очередь, Канада также успешно обжаловала в ОРС бразильскую программу субсидирования экспорта самолетов Embraer [37]. Обе страны получили право на применение санкций друг против друга за неисполнение решений ОРС. Судя по всему, в итоге Бразилия и Канада пришли к компромиссу, отказавшись от введения санкций и сохранив практически в неприкосновенности свои программы субсидирования. Условия данного соглашения не были сообщены в ОРС ВТО, и о его наличии можно лишь догадываться по поведению сторон.

Но вернемся к упомянутому выше мировому соглашению межу ЕС, Канадой и США в отношении запрета ЕС на импорт говядины, выращенной 
с использованием гормонов. Оно интересно не только тем, что предусматривало сохранение уже оспоренного в ОРС запрета, а тем, что предоставляло дополнительные импортные квоты на высококачественное мясо только США и Канаде. Данный факт можно назвать дискриминационным подходом по отношению к другим членам ВТО, а само соглашение - признать соответствующим праву ВТО лишь с очень большой натяжкой. Мировое соглашение между Южной Кореей и Японией по спору Japan - Import Quotas on Laver [38] предусматривало обязательство Японии предоставлять импортные квоты на красные водоросли только Южной Корее. Судя по всему, для государств-членов ВТО требования Договоренности в отношении мировых соглашений оказались слишком жесткими. Поэтому в поисках компромиссных путей решения споров они вышли за их рамки. Это лишний раз подтверждает тезис о том, что в ходе переговоров государства сами решают, что именно они будут считать приемлемым для них исходом торгового спора в ВТО. При этом не исключено, что итогом такого компромисса может стать даже сохранение успешно оспоренной в ОРС меры.

\section{6. Практика ОРС ВТО в отношении протоколов о присоединении к ВТО}

В последние годы критику вызывает крайне неоднозначная практика третейских групп и Апелляционного органа по толкованию протоколов о присоединении новых государств к ВТО. Применительно к документам о присоединении новых стран подход ВТО во многом был скопирован с подхода ГАТТ. Однако ВТО фундаментально отличается от ГАТТ, и то, что работало в ГАТТ, оказывается неэффективным в ВТО. Это доказывает неудачная практика ОРС, связанная с настойчивым желанием Китая пересмотреть условия своего членства в ВТО.

С момента создания ВТО в нее вступили 32 государства. Китай присоединился к ВТО в 2001 г., проведя 15 лет в очень тяжелых переговорах. Сейчас, спустя почти 14 лет, в Китае открыто говорят, что присоединение к ВТО состоялось на исключительно невыгодных, не основанных на взаимности и несимметричных для Китая условиях [39, с. 227]. В силу отсутствия опыта и нехватки квалифицированной правовой поддержки Китай принял на себя много неясно прописанных обязательств. Видя в Китае своего основного конкурента, ведущие страны ВТО постарались заложить как можно больше страховочных механизмов в свою пользу. Достаточно сравнить объем Протокола для Китая (103 стр. с приложениями) с двухстраничными протоколами для Эквадора и Кабо-Верде. Сейчас Китай открыто заявляет, что пришло время для того, чтобы устранить это неравенство и привести условия членства страны в ВТО в соответствие с его реальным статусом в мировой экономике. Прекрасно понимая нереалистичность внесения изменений и дополнений в Протокол о присоединении страны в ВТО (для этого нужны годы переговоров и согласие всех государств), Китай решил попробовать сделать это через решения ОРС. 
В данном отношении крайне интересно вынесенное 26 марта 2014 г. решение Третейской группы по делу China rare earth [40]. В этом споре США, ЕС и Япония пожаловались в ОРС на различные меры тарифного (пошлины) и нетарифного (квотирование) регулирования, введенные Китаем в 2009 г. на экспорт редкоземельных металлов, вольфрама и молибдена. Третейская группа признала действия Китая не соответствующими нормам ВТО. Многоплановость значения этого решения можно понять, лишь рассматривая его в историческом, политическом и экономическом контексте.

Нужно отметить, что ВТО не относится к международным договорам, к которым можно присоединиться, лишь подписав (ратифицировав) многочисленные соглашения ВТО. Любое государство, изъявившее желание вступить в ВТО, должно заплатить за «входной билет», при этом его цены, как показывает практика ВТО, для разных государств могут разительно различаться. Под «входным билетом» обычно понимают набор из тарифных и нетарифных уступок, гарантий по доступу на определенные рынки и других вполне конкретных обязательств, сделанных в ходе переговоров о вступлении данного государства, в дополнение к общим для всех членов ВТО обязательствам. В литературе и даже в официальных документах такие обязательства называются «обязательства ВТО-плюс». Документы о присоединении к ВТО какого-либо государства могут также предусматривать ограничения для вступающего государства в части использования прав, предоставляемых соглашениями ВТО («ВТО-минус»). Условия, на которых государство присоединяется к ВТО, прописываются в протоколе о присоединении. Доклад рабочей группы содержит как обязательства, которые инкорпорируются в протокол о присоединении, так и другие условия, например объяснения и заверения, сделанные присоединяющимся государством.

В центре спора оказался п. 11.3 Протокола о присоединении Китая к ВТО, в соответствии с которым он должен был устранить все экспортные налоги и пошлины на все товары, за исключением тех, которые специально поименованы в приложении 6 к Протоколу (редкоземельные металлы туда не вошли). Китай обосновывал правомерность введенных мер, ссылаясь на ст. ХХ ГАТТ 1994 г. «Общие исключения». Данная статья разрешает применять меры, идущие вразрез с правилами ГАТТ, если эти меры необходимы для защиты здоровья человека (ст. XX (в)) и сохранения невозобновляемых природных ресурсов (ст. XX $(g))$. Китай настаивал, что эти исключения распространяются не только на положения ГАТТ 1994 г., но и на Протокол о присоединении Китая к ВТО. Применительно к рассматриваемому делу полный запрет на введение экспортных пошлин для Китая было «обязательством ВТО-плюс», так как ВТО в целом исходит из того, что у каждого государства есть право вводить экспортные пошлины для регулирования своей экономики. В свою очередь, запрет на использование Китаем исключений, предусмотренных ст. XX ГАТТ (на этом настаивали заявители жалобы), это - пример условий «ВТО-минус», так как предполагается, что в принципе такие исключения доступны для всех государств-членов ВТО [41, с. 483-522]. 
Материалы, о которых шла речь в споре, широко используются в первую очередь при производстве полупроводников, микрочипов и других компонентов для продукции высоких технологий. На момент введения экспортных ограничений Китай являлся фактически монополистом в производстве таких материалов, занимая 95\% рынка, но располагая лишь 37\% мировых запасов. При этом добыча указанных материалов требует применения крайне токсичных субстанций и зачастую приводит к заражению воды и почвы, а также к высокому уровню радиации. Иными словами, на момент вступления в ВТО Китай воспринимался как грязная сырьевая кладовая для развитых стран, которые всеми силами хотели сохранить сложившееся разделение труда и не разрабатывать собственные месторождения.

Очевидная сложность для Китая при рассмотрении спора состояла в том, что в 2012 г. в решении по делу China - Raw Materials [42] Апелляционный орган уже заявил, что не видит каких-либо оснований в Протоколе о присоединении, которые давали бы Китаю право применить ст. ХХ ГАТТ к обязательствам, установленным в п. 11.03 Протокола, так как в этом пункте Протокола ничего не говорится ни по этому поводу, ни про право Китая регулировать свою экономику.

Перед третейской группой, которая, судя по всему, сочувствовала аргументам Китая, встала проблема квазипрецедентного характера решений ОРС. Все международные суды так или иначе стараются выстроить свою устойчивую и непротиворечивую судебную практику. В ВТО тон задает Апелляционный орган, который требует от третейских групп следовать выводам и аргументам, сделанным ранее в его решениях.

В рассматриваемом деле Третейская группа подчеркнула, что толкование соглашений ВТО, при котором суверенные государства не могут предпринять меры, необходимые для защиты окружающей среды и здоровья человека, является несовместимым с предметом и целью Соглашения о ВТО. С точки зрения Третейской группы, такой результат может даже быть сочтен как «очевидно абсурдный или безосновательный».

Однако, учитывая позицию Апелляционного органа, Третейская группа заявила, что Китай не представил никаких убедительных доводов для того, чтобы Третейская группа смогла отойти от выводов, уже сделанных ранее в решении по делу China - Raw Materials. Следуя этой логике, Третейская группа также пришла к выводу, что Протокол о присоединении не дает Китаю права использовать исключения, предусмотренные ст. ХХ ГАТТ, применительно к обязательствам Китая по п. 11.3 Протокола.

При этом мнения членов Третейской группы при оценке ситуации разделились. В особом мнении одного из ее членов было отмечено, что текст п. 11.3 Протокола является положением «ВТО-плюс», и в тексте этого пункта нет ничего о его связи со ст. ХХ ГАТТ. В силу этого, если Китай очевидным 
образом не отказался в Протоколе от применения ст. ХХ ГАТТ (что он не сделал), то он вправе применять общие исключения, предусмотренные данной статьей, для обоснования правомерности своих внутренних мер.

Решение Третейской группы уже обжаловано обеими сторонами спора в Апелляционный орган. Россия активно поддерживает Китай, выступая в процессе в качестве третьей стороны, причем делает это из принципиальных соображений. В отличие от Китая Протокол о присоединении России уже содержит некую оговорку о том, что Россия будет исполнять свои обязательства по Протоколу в отношении экспорта в соответствии с ГАТТ 1994. Однако никто не знает, будет ли этого достаточно для того, чтобы в случае необходимости прибегать к исключениям, предусмотренным ст. ХХ ГАТТ. Судя по тексту заявления, сделанного Россией при рассмотрении дела, она явно чувствует себя некомфортно. Из текста заявления видно, что в ходе переговоров ей обещали тот же статус, что есть у всех членов ВТО, включая право на использование исключений, предусмотренных ст. ХХ ГАТТ. Обещания звучали настолько убедительно, что Россия согласилась снять свое предложение о введении специальной оговорки о том, что обязательства, взятые на основании Протокола о присоединении, не означают отказа от прав, предоставляемых членам BTO $^{1}$ [43, с. 18-19]. Реальность же в ВТО оказалась иной.

Такая практика третейских групп и Апелляционного органа в отношении протоколов о присоединении вызвала волну резкой критики. Исследователи отмечают, что отсутствие убедительной доктрины о правомерности и легитимности протоколов о присоединении имеет серьезные практические последствия, поскольку создает неопределенность в отношении прав и обязанностей вступающих стран по отношению к другим членам ВТО [41, с. 53]. Без убедительных ответов остаются и вопросы, почему у вступающих государств должен быть другой статус, нежели у первоначальных членов ВТО (что разительно отличает ВТО от других международных организаций). Вместо того чтобы устанавливать общие для всех правила игры, нормы ВТО о присоединении новых стран на практике являются протекционистскими инструментами. К сожалению, упомянутая выше практика третейских групп и Апелляционного органа в отношении толкования Протокола о присоединении Китая лишь закрепляет такое неравенство.

Еще одной проблемой для Китая в Протоколе о его присоединении может оказаться закрепленное в нем положение о праве частных лиц на торговлю. Аналогов этому праву нет ни в основных соглашениях ВТО, ни в многосторонних документах о защите прав человека [44]. В том, что это именно мина

1 В соответствии со ст. 5 Протокола о присоединении Китай должен наращивать либерализацию доступности и объем права на торговлю. Такое право на торговлю должно включать право на импорт и экспорт товаров Китая. 
замедленного действия, сомневаться не приходится. Отдавая отчет в жестком прагматизме участников переговоров, появление такого права нельзя объяснить ошибкой или излишним романтизмом. Значит, это сознательно внедренное положение должно как-то рано или поздно выстрелить. И вполне возможно, что данный аргумент будет использован именно при разбирательстве споров с Китаем на уровне третейских групп и Апелляционного органа.

Подводя некоторые итоги анализу деятельности ОРС ВТО за почти 20 лет с момента ее создания, автор еще раз хочет подчеркнуть, что многие описанные выше особенности системы рассмотрения споров в данной организации лишь подчеркивают ее гибридный характер. Более того, можно даже сказать, что они, скорее, являются ее достоинствами, нежели недостатками именно в силу ее гибридности, заложенной с самого начала создавшими эту систему государствами. Для России, недавно вступившей в ВТО и лишь набирающейся опыта при разрешении в ней споров, наиболее прагматичным подходом была бы трезвая оценка особенностей данной системы для того, чтобы пытаться их использовать в своих интересах. При этом надо также отдавать себе отчет, что, невзирая на критику со стороны многих исследователей, которые хотели бы видеть усиление именно судебного начала в ОРС, можно с изрядной долей уверенности сказать, что в ближайшем будущем этот орган вряд ли претерпит серьезные изменения. В первую очередь из-за того, что существующий баланс между судебной и дипломатической доминантами в ОРС не только придает самой системе необходимую гибкость и устойчивость, но и в целом устраивает те государства, которые задают на сегодня тон в нем, извлекая максимум пользы для себя. Автор полагает, что у России есть все основания и возможности присоединиться к этим государствам.

\section{Литература}

[1] WTO disputes reach 400 mark // WTO Press release. PRESS/578. 2009. 6 nov.

[2] Шумилов В.М. Право Всемирной торговой организации (ВТО). М.: Юрайт, 2013.

[3] Смбатян А.С. Всемирная торговая организация: уникальность и адекватность // Право ВТО. 2012. № 1.

[4] Alschner W. Amicable settlements of WTO disputes: bilateral solutions in a multilateral system // World Trade Review. 2014. Vol. 13. № 1.

[5] URL: http://www.wto.org/english/tratop_e/dispu_e/dispu_current_status_e.htm

[6] Leitner K., Lester S. WTO Dispute Settlement 1995-2013 - a statistical analysis // Journal of International Economic Law. 2014. Vol. 17. No. 1. P. 191-201. 
[7] Steger D. Establishment of a Dispute Tribunal in the WTO // Trade and development symposium. Perspectives on the Multilateral Trading System. A Collection of Short Essays. URL: http://www.ictsd.org/downloads/2012/02/ debra-stegerestablishment-of-a-dispute-tribunal-in-the-wto.pdf

[8] United States - Measures Affecting Trade in Large Civil Aircraft (Second Complaint). WT/DS353/AB/R, adopted 23 march 2012.

[9] European Communities - Measures Affecting Trade in Large Civil Aircraft, WT/DS316/R, adopted 1 june 2011.

[10] WTO dispute settlement statistics, 1 january 1995 - 23 september 2011.

[11] Davey W.J. Expediting the Panel Process in WTO Dispute Settlement / M.E. Janow, V. Donaldson, A. Janovich (eds.) // The WTO governance, dispute settlement and developing countries (Juris 2008). P. 409-470.

[12] Busch M., Pelc K. Does the WTO need a permanent body of panelists? // Journal of International Economic Law. 2009. Vol. 12. No. 3. P. 579-594.

[13] Petersmann E. Ten years of the WTO dispute settlement system: past, present and future // Journal of international law and policy. 2004. Vol. III. P. 1-48.

[14] Australia - Measures Affecting Importation of Salmon ("Australia Salmon"). WT/DS18/AB/R, adopted 6 november 1998.

[15] Kelly T. The WTO environment and health and safety standards // The World Economy. 2003. Vol. 26. Is. 2. P. 131-151.

[16] EC - Measures Concerning Meat and Meat Products (Hormones) (European Communities - Hormones). WT/DS26/AB/R, WT/DS48/AB/R, adopted 13 february 1998. Para. 89.

[17] India - Patent Protection for Pharmaceutical and Agricultural Chemical Products, WT/DS50/AB/R, adopted 16 january 1998. Para. 46.

[18] Cottier Th. The WTO Permanent Panel Body A Bridge Too Far? // Journal of International Economic Law. 2003. Vol. 6. No. 1. P. 187-202.

[19] Bourgeois H.J. Comment on a WTO Permanent Panel Body // Journal of International Economic Law. 2003. Vol. 6. No. 1. P. 211-214.

[20] Shoyer A.W. Panel Selection in WTO Dispute Settlement Procedures // Journal of International Economic Law. 2003. Vol. 6. No. 1. P. 203-209. 
[21] Weiler J.H. The Rule of Lawyers and the Ethos of Diplomats: Reflections on the Internal and External Legitimacy of WTO Dispute Settlement // Harvard Jean Monnet Working Paper. 2000. No. 9.

[22] Bello J. The WTO Dispute Settlement Understanding: Less Is More // American Journal of International Law. 1996. Vol. 90. P. 416-417.

[23] Charnovitz S. The Enforcement of WTO Judgment // The Yale Journal of international Law. 1999. Vol. 34. P. 558-566.

[24] Jackson J.H. International Law Status of WTO Dispute Settlement Reports: Obligation to Comply or Option to "Buy Out"? // American Journal of international Law. 2004. Vol. 98. P. 109-125.

[25] WTO Current status of disputes. URL: http://www.wto.org/english/ tratop_e/dispu_e/dispu_current_status_e.htm

[26] United States - Section 110(5) of US Copyright Act. WT/DS160/R, adopted 15 june 2000.

[27] United States - Subsidies on Upland Cotton. WT/DS267/AB/R, adopted 21 march 2005.

[28] Memorandum of understanding between the Government of the United States of America and the Government of Federative Republic of Brazil reading a fund for technical assistance and capacity building with respect to the Cotton dispute (WT/DS267) in the WTO. URL: http://www.brazilcouncil.org/sites/default/files/ MOUonaFundforTAandCB-Apr202010.pdf

[29] Revised Memorandum of understanding with the United States of America Regarding the Importation of Beef from Animals Not Treated with Certain Growth-Promoting Hormones and Increased Duties Applied by the United States to Certain Products of the European Union, 21 october 2013. URL: http://eur-lex.europa.eu/LexUriServ/LexUriServ.do?uri=OJ:L:2014:027:000 2:0006:EN:PDF.

[30] Grimmett J. WTO Dispute Settlement: Status of U.S. Compliance in Pending Cases Congressional Research Service. 2012. 23 apr.

[31] Horlick G., Coleman J. The compliance problem of the WTO // Arizona Journal of International and Comparative Law. 2007. Vol. 24. No. 1. P. 142.

[32] President's Statement on Steel Proclamation. 2003. 4 dec. URL: http://georgewbush-whitehouse.archives.gov/news/ releases/2003/12/20031204-5.html 
[33] Zimmermann C. The Neglected Link Between the Legal Nature of WTO Rules, the Political Filtering of WTO Disputes, and the Absence of Retrospective WTO Remedies // /Trade, Law and Development. 2012. Vol. 4. No. 1. P. 251-267.

[34] Tranchtman Bananas, direct effect and compliance // European Journal of international Law. 1999. Vol. 10. No. 4. P. 678.

[35] Notification of Mutually Agreed Solution, United States Reviews of Countervailing Duty on Softwood Lumber from Canada (US-Softwood Lumber). WT/DS311/2. 16 november 2006.

[36] Framework for a Mutually Agreed Solution to the Cotton Dispute in the WTO. WT/DS267. URL http://trade.ec.europa.eu/doclib/docs/2010/ september/tradoc_146678.pdf

[37] Canada - Measures Affecting the Export of Civilian Aircraft, Recourse by Brazil to Article 21.5 of the DSU, WT/DS70/AB/RW, adopted 4 august 2000.

[38] DS46. Decision by the Arbitrators of 28 august 2000 № WT.

[39] DS46/ARB.

[40] Japan - Import Quotas on Dried Laver and Seasoned Laver, Notification of Mutually Agreed Solution, WTO/DS/323.

[41] Xiaohui $W u$. No longer outside, not yet equal: rethinking China's membership in the World Trade Organization // Chinese Journal of International Law. 2011. Vol. 10. Is. 2. P. 227.

[42] China - Measures Related to the Exportation of Rare Earths, Tungsten and Molybdenum. WTO/DS/431P, adapted 26 march. 2014.

[43] Julia Ya QIN. "WTO-Plus" Obligations and Their Implications for the World Trade Organization Legal System. An Appraisal of the China Accession Protocol // Journal of World Trade. 2003. Vol. 37. No. 3. P. 483-522.

[44] China - Measures Related to the Exportation of Various Raw Materials. WT/DS394/AB/R/WT/DS395/AB/R/WT/DS398/AB/R, adopted 22 february 2012. 
Ispolinov A. ${ }^{1}$

\section{0th anniversary of the WTO: \\ critical overview of the practice of the Dispute Settlement Body}

In a present article the author considers the activity of the WTO Dispute Settlement Body and argues that the starting point for its analysis shall be an understanding of the DSB as highly specific institution combining both diplomatic and judicial components. Such understanding could be useful in explaining also specific features of the DSB like a specific character of decisions, retaliation, evolution of the role and types of the amicable agreements in the WTO.

Key words: Disput Settlement Body WTO, compulsory force of DSB decisions, sanctions, amicable agreements.

1 Ispolinov Alexey Stanislavovich - the Head of International law department of the Faculty of Law of the Lomonosov Moscow State University, Candidate of Sciences (Law), docent. 